\title{
Identification of warning signs for prevention of in-hospital cardiorespiratory arrest*
}

\author{
Beatriz Tessorolo Souza ${ }^{1}$ \\ Maria Carolina Barbosa Teixeira Lopes ${ }^{1}$ \\ Meiry Fernanda Pinto Okuno ${ }^{1}$ \\ Ruth Ester Assayag Batista ${ }^{1}$ \\ Aécio Flávio Teixeira de Góis ${ }^{2}$ \\ Cássia Regina Vancini Campanharo ${ }^{1}$
}

\begin{abstract}
Objective: to identify the occurrence of warning signs and changes in vital signs in individuals who experienced in-hospital cardiorespiratory arrest and correlate them with the occurrence of this event. Method: this is a retrospective, analytical and quantitative study that included 218 medical records of patients who suffered in-hospital cardiorespiratory arrest and identified warning signs and alterations in vital signs. Mean, standard deviation, median, minimum and maximum values were calculated for the continuous variables, and frequency and percentage for the categorical variables. We compared the age and occurrence of cardiorespiratory arrest with the occurrence of warning signs using the Chi-Square Test and the Mann Whitney non-parametric test ( $p$-value $<0.05$ ). Results: $62.1 \%$ of the patients presented signs and symptoms of shock, $44.9 \%$ of neurological alteration, $40.4 \%$ of malaise, $15.2 \%$ presented signs suggestive of acute coronary syndrome, and $25.9 \%$ presented mental confusion. In the last measurement of vital signs before cardiorespiratory arrest, the majority of patients had altered abnormal (32.6\%) and severely abnormal (23.9\%) heart rate, and abnormal (37.1\%) and severely abnormal $(27.0 \%)$ respiratory rate. Conclusion: the warning signs identified were: shock, neurological signs, malaise and acute coronary syndrome. The prevalent changes in vital signs were: heart rate, respiratory rate and $\mathrm{O}_{2}$ saturation. Patients with severely abnormal systolic blood pressure were not discharged and those with abnormal respiratory rate did not survive 6 months after cardiorespiratory arrest.
\end{abstract}

Descriptors: Emergency Nursing; Cardiopulmonary Arrest; Vital Signs; Hospital Care; Secondary Prevention; Quantitative Research.

\footnotetext{
* Supported by Fundação de Amparo à Pesquisa do Estado de São Paulo (FAPESP), Brazil, grant \#2016/17829-6

1 Universidade Federal de São Paulo, Escola Paulista de Enfermagem, São Paulo, SP, Brazil.

2 Universidade Federal de São Paulo, Escola Paulista de Medicina, São Paulo, SP, Brazil.
}

\section{How to cite this article}

Souza BT, Lopes MCBT, Okuno MFP, Batista REA, Goís AFT, Campanharo CRV. Identification of warning signs for prevention of in-hospital cardiorespiratory arrest. Rev. Latino-Am. Enfermagem. 2019;27:e3072. [Access $\leftarrow \neq \uparrow$ ]; Available in $i$ DOI: http://dx.doi.org/10.1590/1518-8345.2853.3072 


\section{Introduction}

The nursing team is often the first to identify clinical changes in patients. These changes can be easily detected by monitoring vital signs (VS) and careful observation of the patient's facial expressions and neuro-emotional behavior. The identification of changes in deviant values is accompanied by an increased risk of adverse clinical events such as cardiorespiratory arrest (CRA). Early identification of abnormalities offers the opportunity for timely intervention and increased survival with better quality of life of patients(1).

CRA is characterized by sudden interruption of the heart rate, respiratory movements and immediate loss of consciousness, leading to irreversible brain damage and death if adequate measures to stabilize the patient are not taken immediately(2).

Annually, more than 200,000 adults undergo in-hospital CRA in the United States ${ }^{(3-4)}$, and many of these events could have been prevented ${ }^{(5-6)}$ through early identification of signs and initiation of appropriate therapy ${ }^{(5)}$.

CRA is rarely a sudden event. It is the result of progressive deterioration of respiratory and circulatory function (7). CRA in hospitalized patients is often preceded by signs of clinical worsening. Early detection and intervention in situations of clinical instability is an opportunity to prevent CRA in these patients and increase the safety of hospitalized patients( ${ }^{(8)}$.

Studies have demonstrated the relationship between abnormalities in routine measures of VS and poor outcomes, including death and in-hospital CRA ${ }^{(9-10)}$. An American study found a high prevalence of abnormal VS preceding CRA. Patients with three abnormal VS had $20 \%$ higher mortality than those without alterations, showing the direct relationship between these changes and the increase in in-hospital mortality rate ${ }^{(11)}$. A study in Japan implemented an Early Warning Score (EWS) system in which each change in a vital signal (systolic blood pressure, heart rate, respiratory rate, temperature, level of consciousness) was given a value of 0-3; the total score corresponded to the sum of these values. Scores greater than or equal to 7 corresponded to "danger zone", that is, a greater possibility of acute deterioration. Patients in the "danger zone" received early interventions. After the implantation of the EWS, the rate of in-hospital CRA per 1000 admissions decreased from 5.21 to $2.05^{(12)}$.

The measurement of VS, which is usually the responsibility of the nursing team, is a routine and extremely important hospital activity, because it determines the health status of the individuals, the evolution of the clinical picture, and can predict clinical deterioration ${ }^{(1)}$.

The first link in the chain of survival for in-hospital CRA is surveillance of patients and identification of warning signs. The literature cites changes in VS as risk factors for CRA. The performance of the nursing team in the periodic verification of VS is relevant in this scenario, to the identification of early changes that may precede CRA and other cardiovascular emergencies, thus increasing patient safety.

The objective of this study was to identify the occurrence of warning signs and changes in VS in individuals who presented in-hospital CRA and correlate the presence of warning signs and changes in VS with the occurrence of CRA.

\section{Method}

This is a retrospective, analytical and quantitative study performed at the Emergency Unit of the Hospital of São Paulo (HSP). The HSP is a large, high complexity, university hospital that offers multiprofessional health care in ambulatory, hospitalization and urgency and emergency modalities ${ }^{(13)}$.

Data collection was performed from October 2016 to January 2017, retrospectively, through the analysis of medical records of patients. A total of 218 medical records of patients who experienced CRA in the Clinical Emergency sector from January 2011 to February 2012 were included in the study. Patients who had a CRA who had out-of-hospital cardiac arrest were excluded. Variables of patients were collected using an instrument created by the researcher, including: gender, age, skin color, neurological status before CRA, and presence of previous CRA. The variables related to the CRA were: initial rhythm, time intervals between cardiopulmonary resuscitation (CPR) attempts, defibrillation, airway clearance, and epinephrine and CRA duration. Warning signs such as neurological changes (lowering of consciousness level, convulsion, hemiparesis, deviation of rhyme and lip movement, dysarthria, slurred speech and/or speech different from the usual pattern), symptoms of acute coronary syndrome (ACS) (chest pain, skin color and humidity changes, and decreased temperature at the extremities - pale, grayish, moist or cyanotic extremities) and changes in vital signs were recorded in the 24 hours preceding CRA. We also investigated whether there was a return of spontaneous circulation and survival in the first 24 hours, at discharge, and six months and one year after the CRA. 
In the case of patients who died, the cause of death was investigated.

Descriptive and inferential analyses of data were carried out in the SPSS software (Statistical Package for the Social Sciences, version 11.5 for Windows). Statistical analyses included the calculation of mean, median, minimum and maximum values of the continuous variables. In the case of the categorical variables, frequencies and percentages were calculated. The QUI-Square test was used to calculate the occurrence of death with variables of interest, and, when necessary, the Fisher's exact test or the Likelihood Ratio Test were used. Cox Regression was used to identify factors related to patient survival. A significance level of $5 \%$ ( $p$-value $<0.05$ ) was adopted. The Fisher's exact test was used to compare the evolution of Cerebral Performance Category (CPC) with variables of interest (categorical). The Mann-Whitney test was used to compare the occurrence of death with variables of interest (continuous); a significance level of $5 \%$ ( $p$-value $<0.05$ ) was adopted. The results were presented through tables and graphs. For statistical analysis of VS, the following values were considered abnormal: heart rate $(H R) \leq 60$ or $\geq 100 \mathrm{bpm}$, respiratory rate $(R R) \leq 10$ or $>20 \mathrm{rpm}$ and systolic blood pressure (SBP) $\leq 90 \mathrm{mmHg}$. A subgroup of severely abnormal VS was also considered: $H R \leq 50$ or $\geq 130 \mathrm{bpm}, \mathrm{RR} \leq 8$ or $\geq 30 \mathrm{rpm}$ and $\mathrm{SBP} \leq 80 \mathrm{mmHg}^{(11)}$.

This study is part of a doctoral thesis approved by the Research Ethics Committee of the Federal University of São Paulo (protocol 0030/2011). Considering that this study is observational and that data collection was done by means of medical records, not causing any type of interference in the sector or in patient care, the study was exempt from informed consent term.

\section{Results}

The mean age of the study population was 66.8 years, with $52.3 \%$ of males and $47.7 \%$ of females. Regarding color, $71.1 \%$ declared to be white, $15.1 \%$ yellow, $10.6 \%$ black and $3.2 \%$ brown. Most were independent in activities of daily living (53.9\%) and had not had a previous CRA (97.7\%).

According to Table 1, the most frequent initial rhythm of CRA was pulseless electrical activity (57.4\%), and the mean time between collapse and onset of CPR maneuvers was 0.8 minutes. The mean time between onset of CPR and the 1st shock was 9.4 minutes; between onset of CPR and airway clearance was 5.5 minutes; and between onset of CPR and administration of the 1 st dose of epinephrine was 1.7 minutes. The total duration of CPR was 16.1 minutes, on average.

Table 1 - Initial cardiac arrest rhythm and time intervals during care in the studied population. São Paulo, SP, Brazil, 2017

\begin{tabular}{|c|c|}
\hline Clinical variables & $n(\%)$ \\
\hline \multicolumn{2}{|l|}{ Initial rhythm } \\
\hline Ventricular fibrillation & $9(4.2)$ \\
\hline Pulseless ventricular tachycardia & $6(2.8)$ \\
\hline Pulseless electrical activity & $124(57.4)$ \\
\hline Asystolia & $77(35.6)$ \\
\hline Total patients & 216 \\
\hline \multicolumn{2}{|l|}{ Time collapse - onset of CPR } \\
\hline Mean (SD) & $0.8(2.8)$ \\
\hline Median (Minimum - Maximum) & $0(0-21)$ \\
\hline Total patients & 157 \\
\hline \multicolumn{2}{|l|}{ Time onset of CPR ${ }^{\star}$ - 1st shock } \\
\hline Mean (SD) & $9.4(12.2)$ \\
\hline Median (Minimum - Maximum) & $4(0-55)$ \\
\hline Total patients & 33 \\
\hline \multicolumn{2}{|l|}{ Time onset of CPR ${ }^{*}$ UAW clearance ${ }^{\dagger}$} \\
\hline Mean (SD) & $5.5(6.0)$ \\
\hline Median (Minimum - Maximum) & $4(0-35)$ \\
\hline Total patients & 92 \\
\hline \multicolumn{2}{|l|}{ Time onset of $C P R^{*}$ - 1st epinephrine } \\
\hline Mean (SD) & $1.7(2.5)$ \\
\hline Median (Minimum - Maximum) & $1(0-17)$ \\
\hline Total patients & 150 \\
\hline \multicolumn{2}{|l|}{ Time onset of $C P R^{*}$ - end of $C P R^{*}$} \\
\hline Mean (SD) & $16.1(13.0)$ \\
\hline Median (Minimum - Maximum) & $13(2-76)$ \\
\hline Total patients & 165 \\
\hline
\end{tabular}

Concerning the warning signs for the occurrence of CRA ( $n=198), 62.1 \%$ of the patients presented signs and symptoms of shock; $44.9 \%$ presented neurological signs; $40.4 \%$ presented malaise; and $15.2 \%$ had signs and symptoms suggestive of acute coronary syndrome.

The mean values of the following variables in the 24 hours preceding CRA in the studied population were: respiratory rate: $25.5 \mathrm{bpm}$; systolic blood pressure: $98.3 \mathrm{mmhg}$; diastolic blood pressure: $60.0 \mathrm{mmhg}$; mean blood pressure: $60.1 \mathrm{mmhg}$; heart rate: $84.7 \mathrm{bpm}$; temperature: $36.3^{\circ} \mathrm{C}$; oxygen saturation: $90.4 \%$; and mental confusion: $25.9 \%$ of the patients. These data are shown in Table 2. 
Table 2 - Vital signs, oxygen saturation and level of consciousness in the 24 hours preceding the cardiorespiratory arrest in the studied population. São Paulo, SP, Brazil, 2017

\begin{tabular}{lc}
\hline \multicolumn{1}{c}{ Clinical variables } & $\mathbf{n}(\%)$ \\
\hline Respiratory frequency & \\
Mean (Standard deviation) & $25.5(8.7)$ \\
Median (Minimum-Maximum) & $24(8-48)$ \\
Total patients & 116 \\
\hline
\end{tabular}

\begin{tabular}{lc}
\hline Systolic Blood Pressure & \\
Mean (SD) & $98.3(33.2)$ \\
Median (Minimum - Maximum) & $97.5(30-200)$ \\
Total patients & 180 \\
\hline Diastolic Blood Pressure & $60(22.2)$ \\
Mean (SD) & $60(20-131)$ \\
Median (Minimum - Maximum) & 180 \\
\hline
\end{tabular}

\begin{tabular}{lc}
\hline Mean Blood Pressure & \\
Mean (SD) & $60.1(35.8)$ \\
Median (Minimum - Maximum) & $63.7(0-145)$ \\
Total patients & 218 \\
\hline Heart rate & \\
Mean (SD) & $84.7(30.2)$ \\
Median (Minimum - Maximum) & $84(8-148)$ \\
Total patients & 184 \\
\hline Temperature & \\
Mean (SD) & $36.3(1.6)$ \\
Median (Minimum - Maximum) & $36(32-41.6)$ \\
Total patients & 117 \\
\hline Oz saturation & \\
Mean (SD) & $90.4(8.5)$ \\
Median (Minimum - Maximum) & $93(35-100)$ \\
Total patients & 144 \\
\hline Level of consciousness & $\mathrm{n}(\%)$ \\
Alert & $23(20.5)$ \\
Confuse & $29(25.9)$ \\
Responds to pain & $7(6.3)$ \\
Unconscious & $218.8)$ \\
\hline Sedated & \\
\hline
\end{tabular}

Regarding outcomes, $48.6 \%$ had return of spontaneous circulation, with $16.8 \%$ surviving the first 24 hours, $6.3 \%$ surviving at hospital discharge, 5.3\% surviving six months after discharge, and $4.9 \%$ surviving one year after the discharge. Regarding the reasons of death, $92(42.6 \%)$ died from infection, 52 (24.1\%) from cancer, $39(18.1 \%)$ from cardiovascular diseases, $3(1.4 \%)$ from trauma, 95 (44\%) due to other causes.

According to Table 3, most survivors at discharge were independent in daily life activities 6 months and 1 year after the CRA, with CPC 1 or 2 .

Table 3 - Neurological state after cardiorespiratory arrest in the study population. São Paulo, SP, Brazil, 2017

\begin{tabular}{lc}
\hline \multicolumn{1}{c}{ Clinical variables } & $\mathrm{n}(\%)$ \\
\hline CPC* at discharge $^{*}$ & $3(27.3)$ \\
1 & $6(54.5)$ \\
3 & $1(9.1)$ \\
4 & $1(9.1)$ \\
Total patients & 11 \\
\hline CPC* 6 months after CRA & \\
1 & $5(55.6)$ \\
2 & $3(33.3)$ \\
3 & $1(11.1 \%)$ \\
Total patients & 9 \\
\hline CPC* 1 year after CRA & \\
1 & $5(62.5)$ \\
2 & $3(37.5)$ \\
Total patients & 8 \\
\hline *CPC - Cerebral Performance Category &
\end{tabular}

Table 4 shows the association of socio-demographic variables, neurological state before CRA, the initial CRA rhythm, and the outcomes with the warning signs presented by the patients in this study.

Regarding the occurrence of neurological signs, patients who presented these signs had a higher percentage of return of spontaneous circulation (62.9\%) and survival in the first 24 hours after the event (22.5\%) when compared to those who did not $(36.7 \%$ and $9.2 \%$, respectively). Among patients who presented signs of Acute Coronary Syndrome (ACS), there was a predominance of patients with CPC 1 (33.3), followed by patients with CPC $2(14.4 \%)$, over patients with CPC 3 and 4/5, which corresponded to $4.3 \%$ and $0 \%$, respectively. Patients who presented VF as the initial CRA rhythm had a higher percentage of signs of ACS (57.1\%) than patients with other rhythms. Patients with signs of ACS had a higher percentage of discharge (13.3\%) and death due to cardiovascular disease (CVD) (33.3\%) than those who did not present such signs. 
A higher mean age (69.3) and rate of death due to infections (52\%) were observed in patients who presented signs of shock when compared to patients who did not presented such signs (63.4 years and $37 \%$, respectively). Patients without signs of shock had a higher percentage of survival, survival in the first 24 hours after CRA (10.7\%), 6 months after CRA (9.3\%) and 1 year after CRA (9.3\%).

Table 4 - Association warning signs with socio-demographic variables, neurological state before cardiorespiratory arrest, initial cardiac arrest rhythm and outcomes. São Paulo, SP, Brazil, 2017

\begin{tabular}{|c|c|c|c|c|}
\hline \multirow{2}{*}{ Variables of interest } & \multicolumn{2}{|c|}{ Neurological signs } & \multirow{2}{*}{ Total n (\%) } & \multirow{2}{*}{$p$-value } \\
\hline & Yes n (\%) & No n (\%) & & \\
\hline \multicolumn{5}{|l|}{ Return of Spontaneous Circulation ( $N=198)$} \\
\hline Yes & $56(62.9)$ & $40(36.7)$ & $96(48.5)$ & \multirow{2}{*}{0.0002} \\
\hline No & $33(37.1)$ & $69(63.3)$ & $102(51.5)$ & \\
\hline \multicolumn{5}{|l|}{ Survival in the first 24 hours $(\mathrm{N}=198)$} \\
\hline Yes & $20(22.5)$ & $10(9.2)$ & $30(15.2)$ & \multirow{2}{*}{0.0094} \\
\hline \multirow[t]{3}{*}{ No } & $69(77.5)$ & $99(90.8)$ & $168(84.8)$ & \\
\hline & \multicolumn{2}{|c|}{ Signs of ACS* } & \multirow{2}{*}{ Total n (\%) } & \multirow{2}{*}{$p$-value } \\
\hline & Yes n (\%) & No $n(\%)$ & & \\
\hline \multicolumn{5}{|l|}{$\mathrm{CPC}^{\dagger}$ before CRA ( $\left.\mathrm{N}=197\right)$} \\
\hline 1 & $12(33.3)$ & $24(66.7)$ & $36(100)$ & \multirow{4}{*}{$0.0023^{\S}$} \\
\hline 2 & $16(14.4)$ & $95(85.6)$ & $111(100)$ & \\
\hline 3 & $2(4.3)$ & $45(95.7)$ & $47(100)$ & \\
\hline $4 / 5$ & $0(0)$ & $4(100)$ & $4(100)$ & \\
\hline \multicolumn{5}{|l|}{ Initial rhythm ( $N=197)$} \\
\hline Ventricular fibrillation & $4(57.1)$ & $3(42.9)$ & $7(100)$ & \multirow{4}{*}{$0.0296^{\S}$} \\
\hline Pulseless ventricular tachycardia & $1(20)$ & $4(80)$ & $5(100)$ & \\
\hline Pulseless electrical activity & $19(16.1)$ & $99(8.9)$ & $118(100)$ & \\
\hline Asystolia & $6(9)$ & $61(91)$ & $67(100)$ & \\
\hline \multicolumn{5}{|l|}{ Discharge $(\mathrm{N}=196)$} \\
\hline Yes & $4(13.3)$ & $6(6.3)$ & $10(5.1)$ & \multirow{2}{*}{$0.0486^{\|}$} \\
\hline No & $26(86.7)$ & $160(96.4)$ & $186(94.9)$ & \\
\hline \multicolumn{5}{|l|}{ Death due to $\mathrm{CVD}^{\ddagger}(\mathrm{N}=196)$} \\
\hline Yes & $10(33.3)$ & $26(16.7)$ & $36(18.4)$ & \multirow{2}{*}{0.0214} \\
\hline \multirow[t]{3}{*}{ No } & $20(66.7)$ & $140(84.3)$ & $160(81.6)$ & \\
\hline & \multicolumn{2}{|c|}{ Signs of shock } & & \multirow{2}{*}{ p-value } \\
\hline & Yes n (\%) & No $n(\%)$ & 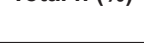 & \\
\hline \multicolumn{5}{|l|}{ Age $(N=198)$} \\
\hline Mean (SD) & $69.3(16.3)$ & $63.4(17)$ & $67.1(16.8)$ & \multirow{2}{*}{0.0113} \\
\hline Median (minimum - maximum) & $72(29-101)$ & $65(17-99)$ & $70(17-101)$ & \\
\hline Survival in the first 24 hours $(N=196)$ & & & & \\
\hline Yes & $2(1.7)$ & $8(10.7)$ & $10(5.1)$ & م007\| \\
\hline No & $119(98.3)$ & $67(89.3)$ & $186(84.8)$ & \\
\hline Survival 6 months after CRA $(N=196)$ & & & & \\
\hline Yes & $1(0.8)$ & $7(9.3)$ & $8(4.1)$ & $00055 \S$ \\
\hline No & $120(99.2)$ & $68(90.7)$ & $188(95.9)$ & 0.0000 \\
\hline Survival 1 year after CRA $(N=195)$ & & & & \\
\hline Yes & $0(0)$ & $7(9.3)$ & $7(3.6)$ & \\
\hline No & $120(100)$ & $68(90.7)$ & $188(96.4)$ & 0.0010 \\
\hline Death due to infection $(N=196)$ & & & & \\
\hline Yes & $64(52)$ & $27(37)$ & $91(46.4)$ & \\
\hline No & $59(48)$ & $46(63)$ & $105(53.6)$ & 年 \\
\hline
\end{tabular}

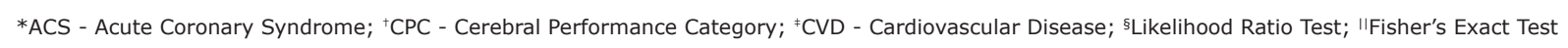


Regarding the last measurement of vital signs before CRA, the majority of patients had abnormal and severely abnormal heart rate $(32.6 \%$ and $23.9 \%$, respectively) and systolic blood pressure (54.4\%) within the normality. Regarding respiratory rate, the majority of patients had abnormal and severely abnormal parameters (37.1\% and $27.0 \%$, respectively), as presented in Table 5.

Table 5 - Last measurement of heart rate, respiratory rate and systolic blood pressure before cardiorespiratory arrest, classified as normal/abnormal. São Paulo, SP, Brazil, 2017

\begin{tabular}{lc}
\hline \multicolumn{1}{c}{ Vital signs } & $\mathrm{n}(\%)$ \\
\hline Heart rate $\left(\mathbf{b p m}^{*}\right)$ & \\
Normal & $80(43.5)$ \\
Abnormal & $60(32.6)$ \\
Severely abnormal & $44(23.9)$ \\
Total patients & 184 \\
\hline Respiratory Rate $\left(\mathbf{r i p m}^{\dagger}\right)$ & \\
Normal & $41(35.3)$ \\
Abnormal & $43(37.1)$ \\
Severely abnormal & $32(27.0)$ \\
Total patients & 116 \\
\hline Systolic Blood Pressure $\left(\mathrm{mmHg}^{\ddagger}\right)$ & \\
Normal & $98(54.4)$ \\
Abnormal & $20(11.1)$ \\
Severely abnormal & $62(34.4)$ \\
Total patients & 180 \\
\hline
\end{tabular}

*bpm - Beats per minute; ${ }^{\dagger}$ ripm - Respiratory incursions per minute; ${ }^{\ddagger} \mathrm{mmHg}$ - Millimeters of Mercury;

\section{Discussion}

In the present study, some socio-demographic characteristics of the patients were similar to those reported in the literature, such as higher proportion of white skin and males. The mean age of the patients in this sample was higher than in other national studies conducted in coronary care units and intensive care units. However, international studies on hospitalization and intensive care units (ICUs) found a higher mean age than that found in the present study ${ }^{(14-19)}$. The most frequent initial rhythm of CRA was pulseless electrical activity (57.4\%) followed by asystolia (35.6\%). In general, these two rhythms are reported as the most common in hospital settings, but asystolia was the most prevalent in an American study evaluating the post-CRA prognosis in patients with chronic diseases aged 18 to more than 80 years $^{(15)}$ and in another study aimed at determining whether early administration of epinephrine in patients with non-shockable initial CRA rhythm is associated with better neurological prognoses ${ }^{(16)}$.

In this study, the mean time interval in minutes between collapse and onset of CPR $\left(0.8^{\prime}\right)$, between onset of CPR and defibrillation (9.4'), and between onset of CPR and clearance of UAW (5.5') were higher than those observed in a prospective study performed in an ICU in Minas Gerais, which presented means of 0.7 '; 7.1'; and $4.8^{\prime}$, respectively ${ }^{(18)}$. This may be related to the fact that this study was performed in an Emergency Service, which may imply a delay in the monitoring of patients presenting CRA, different from the intensive care setting where patients are already monitored. Another aspect that may be related is the fact that this study was retrospective, and the information of interest was taken from hospital records, with possibility of incomplete information.

The mean time interval between onset of CPR and administration of the first dose of epinephrine was 1.7 min in this study, lower than that observed in another study $\left(2.5^{\prime}\right)$. This can be attributed to the fact that the present study was carried out in a university hospital with a large contingent of professionals. Regarding the time between onset and end of CPR, this interval in the studied sample (16.1') was similar to that of another study performed in an ICU $\left(16.3^{\prime}\right)^{(18)}$.

The monitoring of VS of patients allows the detection of changes that increase the risk of adverse clinical events such as CRA. A study conducted in the United Kingdom used the National Early Warning Score, a system based on $\mathrm{HR}, \mathrm{RR}$, blood pressure, $\mathrm{O}_{2}$ saturation, temperature, level of consciousness, and supplemental oxygen use, ranging from 0 to 20, to detect patients at risk of $\mathrm{CRA}^{(10)}$. This study found that mean HR (81 bpm), $\mathrm{RR}(17 \mathrm{rpm}), \mathrm{SBP}(126 \mathrm{mmHg})$, diastolic blood pressure $(70 \mathrm{mmHg})$, temperature $\left(36.7^{\circ} \mathrm{C}\right)$ and $\mathrm{O}_{2}$ saturation $(96 \%)$ were normal ${ }^{(10)}$, differently from the findings of the present study. Another parameter analyzed in the research was the level of consciousness, in which $91.7 \%$ of the patients were alert ${ }^{(10)}$, different from the patients in the present sample in which the majority had altered level of consciousness (79.5\%), being mental confusion the most frequent state $(25.9 \%)$. This difference can be explained by the fact that all patients in this study progressed to CRA.

Similar studies investigated the prevalence of abnormal vital signs and their association with the risk of cardiorespiratory arrest. Among the VS changes described in the literature associated with the risk of CRA 
are abnormal HR, abnormal RR and decreased $\mathrm{SBP}^{(11,20)}$. In the study, all patients with severely abnormal SBP ( $\leq 80 \mathrm{mmHg}$ ) died. Similar results were observed in another study, where mortality increased as SBP values decreased, and patients with SBP $\leq 80 \mathrm{mmHg}$ had a mortality rate above $90 \%{ }^{(11)}$.

In the current study, the majority of patients (37.1\%) presented abnormal respiratory rate, and all patients who presented such change died 6 months after the CRA. However, a study conducted with the objective of examining the association between critical changes in VS and mortality reports that patients with RR $<10 \mathrm{rpm}$ at admission presented $10 \%$ mortality ${ }^{(9)}$, values lower than those found in the present study, and in another study that revealed mortality rates ranging from $80 \%$ to $90 \%$ for RR values > $20 \mathrm{rpm}^{(11)}$.

Regarding pre-CRA CPC, the majority of patients in this sample were classified as CPC 2 (53.9\%). Other national studies also presented higher percentage of patients with CPC $2\left(50 \%{ }^{(21)}\right.$ and $\left.96.7 \%^{(19)}\right)$. The high value of the second study ${ }^{(19)}$ may be associated with the fact that the study only included patients who were discharged after the event.

The CPC of the patients in this study was reassessed at the moment of hospital discharge and at two other times: six months and one year after the CRA. An improvement of the neurological condition was observed over time. At hospital discharge, most patients had CPC 2, whereas in the following assessments, the percentages of CPC 1 were higher. Similar results were obtained in another national study, with progressive improvement of the neurological condition in these time intervals(21).

The association of variables in this study with warning signs presented by the patients showed that the occurrence of neurological signs was associated with higher percentages of return to spontaneous circulation. These results may be related to the state of low cerebral perfusion that can precede CRA, evidenced by lowering of consciousness level, occurrence of seizures, and changes in movement, sensitivity and speech, commonly detected by health professionals ${ }^{(22)}$.

Most patients with signs of ACS presented CPC 1 and 2 before CRA, and as expected, the most frequent CRA rhythm was ventricular fibrillation. Shockable rhythms are common in the first few hours after the onset of ACS symptoms and high-quality immediate CPR and early defibrillation are associated with higher survival and better neurologic outcome in these individuals(22).

Coronary reperfusion is recommended in patients with suspected or confirmed diagnosis of ACS post-
CRA $^{(22)}$. The highest percentages of patients who showed signs of ACS in this study may be related to the early and specialized care given at the studied hospital, which has a cardiologist in the emergency department and an interventional cardiology sector.

In this study, the presence of signs of shock was associated with patients with a higher mean age and higher mortality due to infectious diseases. On the other hand, patients who did not show signs of shock had a higher percentage of discharge and survival in the first 24 hours, six months after CRA and one year after CRA.

Patients who experience a CRA, in most cases, require critical and long-term care after the event and undergo invasive procedures, factors that make them vulnerable to local and systemic infections. A high incidence of sepsis is reported in the world according to literature ${ }^{(23-25)}$ and the increasing number of elderly and patients with chronic diseases are factors, among others, that may contribute to increased mortality in these situations $^{(23)}$. A post-CRA care plan has the potential to avoid early mortality caused by hemodynamic instability and multiple organ failure, as well as late morbidity and mortality resulting from persistent neurological damage. Thus, such measures should be encouraged and disseminated ${ }^{(26)}$.

Among the limitations of this study we can highlight the fact that secondary data were used, obtained from medical records, which sometimes have incomplete information. Furthermore, although the study site was a high-complexity university hospital, it has limited resources and this may have influenced the findings.

This study is of extreme relevance to the practice because the warning signs preceding a CRA are common and may be manifested through changes in vital signs and occurrence of signs and symptoms. The periodical monitoring, according to the needs of the patients, of vital signs and provision of full and uninterrupted care are fundamental activities of the nursing team. By doing so, the nursing team is able to identify signs and symptoms preceding cardiocirculatory collapse in a timely manner.

\section{Conclusion}

In this study, the shock signs, neurological signs, malaise, and ACS were identified as warning signs. The most prevalent VS changes were found in $H R, R R$ and $\mathrm{O} 2$ saturation. Patients with severely abnormal SBP were not discharged and those with abnormal respiratory rate did not survive six months after CRA. 


\section{References}

1. Jorge VC, Barreto M da S, Ferrer ALM, Santos EAQ, Rickli HC, Marcon SS. Nursing team and detection of indicators of worsening condition in emergency room patients. Esc Anna Nery. 2012 Oct/Dec; 16(4):767-74. doi: http://dx.doi.org/10.1590/S141481452012000400018

2. Souza SFM, Silva GNS. Parada cardiorrespiratória cerebral: assistência de enfermagem após a reanimação. Rev Ciênc Saúde Nova Esperança. [Internet]. 2013 Sep [Acesso 12 nov 2016]; 11(2):143-57. Disponível em: http://www.facene.com.br/wp-content/ uploads/2010/11/Parada-cardiorrespiratória-cerebral.pdf 3. Go AS, Mozaffarian D, Roger VL, Benjamin EJ, Berry JD, Blaha MJ, et al. Heart disease and stroke statistics--2014 update: a report from the American Heart Association. Circulation. 2014 Jan 21; 129(3):e28-292. doi: https:// doi.org/10.1161/CIR.0000000000000558

4. Merchant RM, Yang L, Becker LB, Berg RA, Nadkarni $\mathrm{V}$, Nichol $\mathrm{G}$, et al. Incidence of treated cardiac arrest in hospitalized patients in the United States. Crit Care Med. 2011 Nov; 39(11):2401-6. doi: 10.1097/ cCM.0b013e3182257459

5. Hodgetts TJ, Kenward G, Vlackonikolis I, Payne $\mathrm{S}$, Castle N, Crouch $\mathrm{R}$, et al. Incidence, location and reasons for avoidable in-hospital cardiac arrest in a district general hospital. Resuscitation. 2002 Aug; 54(2):115-23. doi: https://doi.org/10.1016/S03009572(02)00098-9

6. Galhotra S, DeVita MA, Simmons RL, Dew MA, Members of the Medical Emergency Response Improvement Team (MERIT) Committee. Mature rapid response system and potentially avoidable cardiopulmonary arrests in hospital. Qual Saf Health Care. 2007 Aug; 16(4):260-5. doi: http://dx.doi. org/10.1136/qshc.2007.022210

7. Stub D, Smith K, Bernard S, Nehme Z, Stephenson M, Bray JE, et al. Air Versus Oxygen in ST-SegmentElevation Myocardial Infarction. Circulation. 2015 Jun 16; 131(24):2143-50. doi: https://doi.org/10.1161/ CIRCULATIONAHA.114.014494

8. Taguti P da S, Dotti AZ, Araujo KP de, Pariz PS de, Dias GF, Kauss IAM, et al. The performance of a rapid response team in the management of code yellow events at a university hospital. Rev Bras Ter Intensiva. 2013 Jun; 25(2): 99-105. doi: http://dx.doi.org/10.5935/0103507X.20130020.

9. Bleyer AJ, Vidya S, Russell GB, Jones CM, Sujata L, Daeihagh $P$, et al. Longitudinal analysis of one million vital signs in patients in an academic medical center.
Resuscitation. 2011 Nov; 82(11):1387-92. doi: https:// doi.org/10.1016/j.resuscitation.2011.06.033

10. Smith GB, Prytherch DR, Meredith P, Schmidt PE, Featherstone PI. The ability of the National Early Warning Score (NEWS) to discriminate patients at risk of early cardiac arrest, unanticipated intensive care unit admission, and death. Resuscitation. 2013 Apr; 84(4):465-70. doi: https://doi.org/10.1016/j. resuscitation.2012.12.016

11. Andersen LW, Kim WY, Chase M, Berg KM, Mortensen SJ, Moskowitz A, et al. The prevalence and significance of abnormal vital signs prior to in-hospital cardiac arrest. Resuscitation. 2016 Jan; 98:112-7. doi: https://doi. org/10.1016/j.resuscitation.2015.08.016

12. Nishijima I, Oyadomari S, Maedomari S, Toma R, Igei $C$, Kobata $S$, et al. Use of a modified early warning score system to reduce the rate of in-hospital cardiac arrest. J Intensive Care. 2016; 4:12. doi: https://doi. org/10.1186/s40560-016-0134-7

13. Hospital São Paulo - Atendimento Hospitalar. [Internet]. 2012 [cited Apr 14, 2018]. Available from: http://www.hospitalsaopaulo.org.br/atendimentohospitalar

14. Nolan JP, Soar J, Smith GB, Gwinnutt C, Parrott $F$, Power $S$, et al. Incidence and outcome of in-hospital cardiac arrest in the United Kingdom National Cardiac Arrest Audit. Resuscitation. 2014 Aug; 85(8):987-92. doi: https://doi.org/10.1016/j. resuscitation.2014.04.002

15. Terman SW, Shields TA, Hume B, Silbergleit R. The influence of age and chronic medical conditions on neurological outcomes in out of hospital cardiac arrest. Resuscitation. 2015 Apr; 89:169-76. doi: https://doi. org/10.1016/j.resuscitation.2015.01.006

16. Donnino MW, Salciccioli JD, Howell MD, Cocchi MN, Giberson B, Berg K, et al. Time to administration of epinephrine and outcome after in-hospital cardiac arrest with non-shockable rhythms: retrospective analysis of large in-hospital data registry. BMJ. 2014 May 20; 348:g3028. doi: https://doi.org/10.1136/bmj.g3028

17. Morrison LJ, Schmicker RH, Weisfeldt ML, Bigham $B L$, Berg RA, Topjian AA, et al. Effect of gender on outcome of out of hospital cardiac arrest in the Resuscitation Outcomes Consortium. Resuscitation. 2016 Mar; 100:76-81. doi: https://doi.org/10.1016/j. resuscitation.2015.12.002

18. Silva RMFL da, Silva BAG de L e, Silva FJM e, Amaral CFS. Cardiopulmonary resuscitation of adults with inhospital cardiac arrest using the Utstein style. Rev Bras Ter Intensiva. 2016; 28(4):427-35. doi: http://dx.doi. org/10.5935/0103-507x.20160076. 
19. Nacer DT. Sobrevivência a parada cardiorrespiratória: avaliação da performance cerebral. Campo Grande. [Internet]. [Dissertação - Universidade Federal de Mato Grosso do Sul. 2016 [Acesso 15 mar 2017]. Disponível em: https://posgraduacao.ufms.br/portal/trabalhoarquivos/download/2421

20. Hodgetts TJ, Kenward G, Vlachonikolis IG, Payne $\mathrm{S}$, Castle N. The identification of risk factors for cardiac arrest and formulation of activation criteria to alert a medical emergency team. Resuscitation. 2002 Aug; 54(2):125-31. doi: https://doi.org/10.1016/S03009572(02)00100-4

21. Vancini-Campanharo $C R$, Vancini $R L$, Lira $C A B$ de, Lopes MCBT, Okuno MFP, Batista REA, et al. Oneyear follow-up of neurological status of patients after cardiac arrest seen at the emergency room of a teaching hospital. Einstein. 2015; 13(2):183-8. doi: 10.1590/ S1679-45082015AO3286

22. Piegas L, Timerman A, Feitosa G, Nicolau J, Mattos $L$, Andrade $M$, et al. V Diretriz da sociedade brasileira de cardiologia sobre tratamento do infarto agudo do miocárdio com supradesnível do segmento ST. Arq Bras Cardiol. [Internet]. 2015 [Acesso 14 abril 2018];105(2). Disponível em: http://www.gnresearch.org/doi/10.5935/ abc. 20150107
23. Rhodes A, Evans LA, Alhazzani W, Levy MM, Antonelli M, Ferrer R, et al. Surviving Sepsis Campaign: International Guidelines for Management of Sepsis and Septic Shock: 2016. Intensive Care Med. 2017; 43:30477. doi: 10.1007/s00134-017-4683-6

24. Tillmann B, Wunsch H. Epidemiology and Outcomes. Crit Care Clin. 2018; 34(1):15-27. doi: https://doi. org/10.1016/j.ccc.2017.08.001

25. Mayr FB, Yende S, Angus DC. Epidemiology of severe sepsis. Virulence. 2014; 5(1):4-11. doi: https:// doi.org/10.4161/viru.27372

26. Callaway CW, Donnino MW, Fink EL, Geocadin RG, Golan E, Kern KB, et al. Part 8: Post-Cardiac Arrest Care: 2015 American Heart Association Guidelines Update for Cardiopulmonary Resuscitation and Emergency Cardiovascular Care. Circulation. 2015; 132(suppl 2):S465-S82. doi: https://doi.org/10.1161/ CIR0000000000000262 